\title{
The Epistemic Impact of the Etiology of Experience
}

\section{Citation}

Siegel, Susanna. 2013. The epistemic impact of the etiology of experience. Philosophical Studies 162(3): 697-722.

\section{Permanent link}

http://nrs.harvard.edu/urn-3:HUL.InstRepos:5141367

\section{Terms of Use}

This article was downloaded from Harvard University's DASH repository, and is made available under the terms and conditions applicable to Open Access Policy Articles, as set forth at http:// nrs.harvard.edu/urn-3:HUL.InstRepos:dash.current.terms-of-use\#OAP

\section{Share Your Story}

The Harvard community has made this article openly available.

Please share how this access benefits you. Submit a story.

Accessibility 


\section{The Epistemic Impact of the Etiology of Experience* Susanna Siegel \\ forthcoming in Philosophical Studies as a symposium}

Down in the basement of the mind, unconscious processes unfold that give rise to conscious experience. In this paper I argue that those processes can impact the rational role of experience.

Suppose you want to know whether there's any mustard in the fridge. You open the door to look. There's the mustard, in a half-empty jar, sitting in the fridge door. So far, looking in the fridge has given you excellent reason to believe that there's mustard in the fridge. Having a reason to believe is a generic notion, tied to what is epistemically appropriate to believe. Sticking with this generic normative notion, we can say that your perceptual experience provides justification, or equivalently, rational or evidential support for believing p. $^{1}$

The very grammar of "perceptual experiences provide justification" can seem to presuppose that experiences do this all by themselves, or at least that they suffice to do so, absent defeaters. But don't read this into the grammar. Read it in a way that allows (but does not entail) that experiences might provide justification for believing a proposition $p$, only with the help of additional factors, such as having justification for believing other propositions besides $p$, or having the right sort of etiological features, or more generally being had under the right external conditions.

Back in the kitchen, you learn you're probably hallucinating. Intuitively, you now have less reason for believing that there's mustard in the fridge. Relative to a baseline at which our perceptual experiences provide pretty good reason to believe our eyes, the amount of rational support provided by epistemically downgraded experiences is reduced - maybe even eliminated. When the rational support provided by experiences is reduced below the baseline, those experiences are epistemically downgraded.

\footnotetext{
" I'm grateful to many audiences for responses to this paper, which I gave as a talk (often called "The Epistemic Impact of Reasoning in the Basement") at ANU, Barcelona, Barnard, Brandeis, Brown, the Chapel Hill Colloquium, Toronto, Cornell, Miami, NYU, St Andrews, Texas, and Western Ontario. Special thanks to Stew Cohen, Eric Mandelbaum, Nico Silins and Jonathan Vogel for extended discussion, Keith Payne for sharing his research, and John Bengson, David Christensen, Josh Dever, Carrie Jenkins, Matthias Jenny, Simon Leen, Jim Pryor, Eric Rowe, George Salmieri, Josh Schechter, Scott Sturgeon, Jonathan Weisberg, and Ru Ye for their helpful reactions.

${ }^{1}$ Two terminological remarks. First, I use "experience" to abbreviate "perceptual experience", a category that encompasses hallucinations and illusions as well as veridical perceptions, but excludes bodily sensations such as pains and tickles. Second, whether "evidence", "justification" and "rational support" can be used interchangeably (as I do here) is controversial. For instance, Lycan (1988) argues that conservative principles of theory-choice can provide rational support for a theory without providing evidence for it, and Foley (2008) distinguishes between several normative notions in the vicinity. I leave it to readers who oppose the conflation to assess which epistemic normative notion, if any, is best suited to the discussion.
} 
When you learn that you're hallucinating, you learn something about the etiology of experience: it was caused by a disturbance in your brain that didn't arise from any interaction with the mustard. Experiences with this etiology depend relatively less on what you see, and relatively more on an endogenous cause of the hallucination.

In this paradigm case of epistemic downgrade, you're aware that your experience has a nonstandard etiology. But suppose you weren't aware that it had that etiology. Would the etiology by itself, without your being aware of it, introduce an epistemic downgrade? One sentiment here favors the idea that an unwitting hallucination could still give you pretty good reason to believe that there's mustard in the fridge, even though that belief would be false. But different etiologies for experience may pull more strongly in the direction of epistemic downgrade, even when those etiologies remain outside the subject's ken. For instance, consider a fear-ridden subject who strongly suspects that there's a gun in her fridge. She has no evidence at all for her suspicion, but because the prospect frightens her she opens the fridge to check inside. When she looks inside, her suspicion causes her to have an experience as of a gun. Can this fear-ridden subject's gun-experience make it reasonable to confirm the very suspicion that caused that experience in the first place? As theorists, we might have the sense that it can't. The fear-ridden subject may regard herself as having looked very carefully, and seen a gun; but however things may seem to her, by looking in the fridge, she has not acquired much, if any, additional reason to be afraid.

In the gun example, the contents of visual experience are affected by fear and suspicion that the perceiver had before she even looked in the fridge. In principle, the contents of experience could be influenced by other kinds of prior states as well: outright beliefs, expectations, desires, hopes, wishes, doubts, even tickles or itches. Here are some other hypothetical examples:

Anger: Before seeing Jack, Jill fears that Jack is angry at her. When she sees him, her fear causes her to have a visual experience in which he looks angry to her.

Preformationism: Some of the early users of microscopes were spermist preformationists who favored the hypothesis that sperm cells contained embryos, and claimed to see embryos in sperm cells when they looked at those cells under a microscope. ${ }^{2}$ Let's suppose their experiences had embryo-content.

Pliers: When primed with pictures of Black men, White American subjects more often misclassify a tool (pliers) as a gun when asked to indicate by keystroke after $200 \mathrm{~ms}$ which one they have seen (they're told they will see either one or the other), compared with White American subjects who have been primed with pictures of White men. The experiment does not settle how the pliers look to the subject when they respond by pressing the 'gun' key, but let us stipulate that upon seeing the pliers, they have an experience in which they seem to see a gun. ${ }^{3}$

\footnotetext{
${ }^{2}$ For more on this amusing episode in the history of embryology see Pinto-Correira (1997).

${ }^{3}$ Payne (2001). The stipulation is probably contrary to fact. In an unpublished follow-up study done by Payne, participants were given the same primes and other stimuli as in the original
} 
Ouija board: Jack is told that Ouija boards are unreliable but trusts them anyway because he wants to. His board tells him that when he's a subject in the experiment described above, he's going to see a gun, and on this basis he forms the belief that he will see a gun. This expectation causes him to have a gun-experience when he is shown the picture.

Pessimism: Beset by a bad mood (or characteristic pessimism), the people you talk to often seem to wear displeased, critical expressions on their faces.

I'll call 'cognitive penetration' influences on contents of experience by prior mental states of all the sorts listed (so 'cognitive' here is encompassing states not traditionally considered part of cognition). ${ }^{4}$ Cognitive penetration will be discussed in more detail later, but the rough idea is all we need for now. I'll assume that when contents are influenced by cognitive penetration, so is the phenomenal character of experience. This assumption can be taken as a stipulation about the sort of contents that are at issue.

One might doubt that there is any principled basis for holding on to both intuitions about whether etiology alone introduces epistemic downgrades. Why think the etiology of the cognitively penetrated experiences removes some of the justificatory force they might otherwise have, whereas the plain old hallucination remains immune from any potential downgrade by its etiology? Both kinds of etiology for experience are suboptimal, but does the first suboptimal kind affect the rational role of experience in a distinctive way?

In this paper I argue that it does. Experiences, like beliefs, can have rationally assessable etiologies. The cognitively penetrated mustard-experience is epistemically downgraded, by

experiment, but after each trial, they were asked how they reached their verdict on whether the stimulus was a tool or a gun. They were given as much time as they wanted to choose between three options a, labeled by SEE (if they 'saw the stimulus or part of it'), KNOW (if they did not see the stimulus but just knew what it was), or GUESS (if they felt they were just guessing whether they had been shown a tool or a gun). Participants who selected SEE did not make categorization errors, whereas participants who made stereotype-consistent errors (misidentifying tools for guns) overwhelmingly selected KNOW for those trials. If we take participants' reports of their own experiences at face value, then these results count against the suggestion that there is cognitive penetration of a simple kind that produces a gunexperience.

${ }^{4}$ I apply the notion of cognitive penetration to perceptual experience, whereas in discussions by Fodor (1983) and (1984) and Pylyshyn (1999), the notion is applied to early vision. When Pylyshyn (1998) argues that vision is cognitively impenetrable, he is saying that early vision is exclusively the output of a module in Fodor's (1983) sense, and as such is not the product of other cognitive states (though its outputs maybe influenced by perceptual learning). Cognitive penetration in my sense is thus compatible with cognitive impenetrability in Fodor's and Pylyshyn's, so long as the contents of visual experience are not exhausted by the outputs of early vision. 
virtue of arising from an irrational process. In contrast, plain old hallucinations, such as those induced by drugs, arise in ways that are a-rational or as I'll sometimes say, zaplike. ${ }^{5}$

Some reliabilists about justification might happily endorse the conclusion that both kinds of suboptimal etiologies lead to epistemic downgrade, and for the same reason both times: they are not processes leading reliably to true beliefs. ${ }^{6}$ For my purposes, it isn't important to reach a verdict on whether plain old hallucinations do or don't introduce epistemic downgrades. ${ }^{7}$ Even if they do, l'll argue, there is such a thing as an experience with an irrational etiology, such etiologies epistemically downgrade experiences, and barring an assimilation of rationality to reliability, this source of epistemic downgrade is distinct from unreliability. This conclusion it is compatible with a variety of internalist positions about justification, and more generally with the idea that phenomenal character of an experience can bestow justificatory power on it.

As I'll elaborate it, the distinction between rationally assessable and a-rational etiologies of experience does not entail any distinction between rationally assessable and a-rational experiences. Experiences need not be the kind of state that are justified or unjustified, in the sense of being rationally or evidentially well-supported or less well-supported. ${ }^{8}$

The idea that experiences can have etiologies that can be rationally assessed is at odds with traditional ways of drawing the contrast between perception and belief. After elaborating this upshot in section 1, I introduce the Downgrade Principle in section 2, which links certain kinds of cognitively penetrated experiences to epistemic downgrade. Section 3 contains the central defense of the Downgrade Principle. In formulating and defending this principle, I take it for the granted that the very idea of a rationally assessable etiology of experience is coherent. Section 4 explains why it is coherent, and gives reasons to think that some of our experiences may well have this status. Section 5 replies to two objections: that the downgrade intuition is overdescribed, and that its only force applies to experiences that represent complex properties (such as gun, embryo or anger), rather than simple properties such as color and shape. Section 6 concludes the discussion.

${ }^{5}$ The term "zaplike" is less perspicuous (though more exciting) than "a-rational", since it invites us to focus on the fact that the hallucination is caused by a process we're not aware of and can't control. But the same can be true of cognitive penetration. Both kinds of etiology can unfold beneath the first-person radar. The heart of the distinction is the status of those processes as rationally assessable or not.

${ }^{6}$ To a first approximation, process reliabilism holds that the justificational status of a belief depends on how it is caused or causally sustained, and identifies the justified beliefs with beliefs that are caused or sustained by processes that lead to a high proportion of true beliefs. ${ }^{7}$ More generally, I set aside whether any experiences with a-rational etiologies are checkered. ${ }^{8}$ One could define up a notion of justifiedness applies specifically to experiences, tracking the epistemic role they can play in rationally supporting beliefs. Chalmers (forthcoming) briefly considers a notion of 'proto-justification' that operates in something like this way. For my purposes here, the theoretical role of proto-justification is too close to that of the notion of propositional justification to be useful. But if one had use for such a notion, it would then be natural to think of experiences as not only proto-justified but also as standing in their own kind of basing relation to their etiologies, whether they are checkered or not. 


\section{Why it matters whether cognitive penetration can lead to epistemic downgrade}

On a traditional picture, reason and experience are two ultimate arbiters of belief. Both are sources of rational belief, on this picture, but neither source is grounded in reason or experience itself. As an ultimate arbiter of belief, experiences are not themselves susceptible to rational evaluation, and according to some foundationalists, this makes it possible for them to block regresses of justification.

Let's call the Downgrade Thesis the thesis that cognitive penetration can lead to epistemic downgrade. If the Downgrade Thesis is true, then the traditional picture overemphasizes the different epistemological profiles of experience and belief: it says that experiences can be ultimate arbiters of a belief, but beliefs can't, because as Ernest Sosa puts it, "when experiences help explain the rational standing of some other state or action, they do not thereby problematize their own rational standing. Being so passive, they have no such standing." ${ }^{9}$ But if the Downgrade Thesis is true, then experiences, like beliefs, can be formed in ways that diminish their role in justifying subsequent beliefs. Just as beliefs that arise from an ungrounded suspicion or expectation, or a hope or a fear, typically do not rationally support subsequent beliefs formed on their basis, ${ }^{10}$ the same is true of experiences that are checkered by suspicion, expectation, hopes or fears. The cognitively penetrated experiences described above arise from processes that mirror routes to paradigmatically ill-formed beliefs: wishful thinking, fearful thinking, jumping to conclusions, and reaching belief through rationally ungrounded associations or negative affect. ${ }^{11}$

The Downgrade Thesis need not assimilate the epistemological profile of all experiences to that of beliefs. It allows that plain old hallucinations do not lead to epistemic downgrade, and if they don't, then the epistemic features of experiences and beliefs will differ in important ways. Compare a plain old hallucination with an a-rational route to belief. If without your knowing it, a drug made you hallucinate a mustard jar, the intuition goes, the hallucination would provide you with some reason to think that there is mustard in the fridge, and might not be epistemically downgraded at all. ${ }^{12}$ But if God zapped you into merely believing that there

\footnotetext{
${ }^{9}$ Sosa (2007), p. 46. Ultimately Sosa distances himself from this picture.

${ }^{10}$ Some versions of epistemic conservatism would deny that such beliefs are unjustified, if the subject has no clue that the beliefs are based in these ways. I'm setting these views aside here. They could provide a line of defense of phenomenal conservatism against criticisms stemming from cases of cognitive penetration described at the start. Such criticisms are developed in Siegel (2011) and Lyons (forthcoming). For criticisms of epistemic conservatism, see Christensen (1994).

${ }^{11}$ Regarding the pliers-gun experiment, it is an open empirical question what kind of state or disposition the priming in the pliers experiment activates. For discussion of the options, see Siegel (ms). A thorny question is whether the process leading from the prime to the perceptual experience is a-rational.

12 Many internalists and externalists alike acknowledge the force of this intuition (see Goldman 1986 and 1998), though it is rejected by McDowell (2008), who seems to hold that when
} 
was mustard in the fridge, without also providing any perceptual experience of mustard, or any other reasons for thinking so, the resulting belief, even if held very strongly, would seem to be epistemically on par with an unsupported hunch.

If the Downgrade Thesis is true, then experiences as a group are not ultimate arbiters of belief, and the epistemic role of experiences will be cognitively holistic in ways that standard theories of perceptual justification ignore. For instance, standard theories allow that beliefs can defeat experiences, but experiences can be cognitively penetrated without the subject having a justification-defeater as these have traditionally been construed. ${ }^{13}$ Opponents of immediate justification hold that experiences provide justification, only when supplemented with other beliefs, or with the subject's having reason for other beliefs. But the Downgrade Thesis is compatible with immediate justification. ${ }^{14}$

By putting pressure on the traditional picture of the epistemological contrast between experience and belief, the Downgrade Thesis helps to solve a puzzle about why cognitive penetration leads sometimes but not always to epistemic compromise. Some kinds of cognitive penetration, such as those generated by some forms of familiarity or expertise, are epistemologically innocuous, and result in experiences that provide justification at the baseline. ${ }^{15}$ If the irrational status of etiologies of certain cognitively penetrated experiences explains why those experiences are epistemically downgraded, then the fact that other cognitively penetrated experiences lack irrational etiologies may help explain why they don't lead to epistemic downgrade.

\section{The Downgrade Principle}

We can begin with an informal characterization of the kind of etiology of experience that will concern us. Let's say, informally, that an experience has a checkered past (or equivalently, that it is a checkered experience) if it results from a kind of cognitive penetration that is a good candidate for leading to epistemically compromised perceptual beliefs. This informal gloss on checkered experience is all we need to understand their dialectical role in the defense of the Downgrade principle. A proper definition is given in section 4.

Being checkered excludes the kind of cognitive penetration that typically results from expertise and familiarity. Intuitively this kind of cognitive penetration is not in tension with experiences leading to justified belief or knowledge, or with the role of experience in letting us rationally asses prior beliefs, suspicions, or fears to see if they are well-confirmed, or to check whether things really are as bad (or as good) as our mood makes them out to be.

The informal gloss on checkered experience leaves open the exact way in which beliefs based on them could end up epistemically compromised, and indeed leaves open whether beliefs would have to end up epistemically compromised in any way at all. The Downgrade

compared with introspectively indiscriminable veridical experiences, hallucinations always provide less justification. For discussion see Siegel and Silins (forthcoming).

${ }^{13}$ This claim about defeat is defended in Siegel (2011) section 4.2.

${ }^{14}$ For all the Downgrade Thesis says, experiences that provide justification may provide immediate justification. This claim is discussed in Siegel (2011) section 5.

${ }^{15}$ Examples of cognitive penetration by familiarity are discussed in Siewert (1996) and by expertise in Siegel (2010), Chapter 4. 
Principle takes a stand on both issues. According to the Downgrade Principle, by virtue of having a checkered past, an experience is epistemically downgraded: the justification it provides for its contents falls below the baseline.

(DP): An experience E is epistemically downgraded if it has a checkered past.

An experience might be epistemically downgraded with respect to its ability to justify believing some contents, but not with respect its ability to justify believing others. For instance, no matter what kind of cognitive penetration affects an experience, arguably it won't affect its ability to justify self-ascriptions of the experience. In addition, epistemic downgrade can be localized to some contents of an experience without attaching to all of them. For instance, in the anger-example, cognitive penetration leading to Jill's anger-experience might downgrade the experience with respect to its anger-content, but not downgrade it with respect to its contents that characterize the overall layout of the scene (as it might be, Jack walking across the room toward Jill). ${ }^{16}$

Implicit in the idea that epistemic downgrades can be localized is the assumption that the propositions an experience can justify depends in part on its contents. What exactly is the relationship between the contents for which an experience provides justification, and the contents of the experience itself? It is often assumed that experiences with content $P$ provide justification for believing $P$, so that the very same content could be the content of either an experience or a belief. This assumption will be an idealization, if it turns out that perception (including perceptual experience) belongs to a system of representation that differs so radically from belief that it is impossible for perceptions and beliefs to have the same content. But even if contents of experiences and beliefs cannot be shared, there will be some contents of beliefs that are closer to the contents of experience than others. In order to allow that the potential contents of beliefs might differ from the contents of experience, only because of differences in the nature of experience and belief contents generally, I'Il sometimes say that the content $C$ of an experience is close to content $\mathrm{C}^{*}$ of belief. For example, in discussing cases of cognitively penetrated experiences, I'll discuss whether an experience with content $\mathrm{C}$ provides (or, because

${ }^{16}$ If experiences have self-representational contents, such as 'there is a red square and I am having an experience as of a red square', then an epistemic downgrade with respect to the firstorder content could be isolated from an epistemic downgrade with respect to the higher-order contents. Self-representational contents of various sorts are defended by Searle (1983), Chalmers (2004), Kriegel (2009), Siegel (2006). 
of downgrade, fails to provide) justification for close content $C^{*} .{ }^{17}$ For convenience, I often ignore this complication, and talk as if experiences and beliefs could have the same contents. ${ }^{18}$

The downgrade principle can be developed in two ways, depending on whether the notion of epistemic downgrade is tied to doxastic justification or to propositional justification. Doxastic epistemic downgrade, like doxastic justification, is defined in terms of the ways that beliefs are formed, maintained or adjusted. The core idea of doxastic justification is that there is such a thing as forming a belief well or badly. If believing the contents of an experience on the basis of the experience thereby results in a belief that is doxastically unjustified, then the experience is epistemically downgraded, in the sense tied to doxastic justification. The Doxastic Downgrade Thesis ties doxastic downgrades to checkered experiences like this:

\section{Doxastic Downgrade Thesis}

If $S$ forms a first-order belief $B$ with content $P$, on the basis of a checkered experience $E$ with content $\mathrm{P}, \mathrm{B}$ is thereby doxastically unjustified, assuming that $\mathrm{S}$ has no other basis on which she believes $P .^{19}$

The restriction to first-order beliefs excludes psychological self-ascriptions, such as "I see a red cube" and "It looks as if there is a red cube on my left", which intuitively are not subject to epistemic downgrade by checkered experiences.

Paradigms of doxastically unjustified beliefs include beliefs formed by letting an ungrounded suspicion or fear morph into a belief. The Doxastic Downgrade Thesis entails that when ungrounded suspicion or fear morphs into belief by checkering an experience along the way, the belief based on checkered experience is also doxastically unjustified.

A doxastically unjustified belief could simultaneously be justified in a different sense: the subject has good reason for believing what she does, even though these good reasons don't figure in the way her belief is formed - i.e., in its etiology. Sometimes the reasons a person has

${ }^{17}$ Some theorists would say that a belief's content $C^{*}$ is close to an experience content $C$, if $C^{*}$ is a 'conceptualization' of C. (Compare Peacocke (2004), chapter 3 on 'canonical correspondence' between non-conceptual and conceptual content). Others, such as McDowell (1994), hold that experiences could not justify beliefs unless the contents of experience could be believed without any additional transformation. Self-ascriptions of experiences are also close to the contents of experiences, even if the experiences are not self-representing.

${ }^{18}$ Besides cases of 'conceptualization' as Peacocke understand it and self-ascriptions, there is another way in which the content $\mathrm{C}$ of experience might be close to a proposition for which it provides justification, without being identical to it. Suppose that if you see Franco sitting down, the content of your experience would be the same whether you're seeing Franco or Franco's twin. Arguably your experience provides justificatory support for believing a proposition about Franco. Seeing Franco sitting can give you excellent reason to believe that Franco is sitting. This case is discussed in Silins (2011).

${ }^{19}$ The last qualification is needed because in principle, $\mathrm{S}$ could have independent evidence for $p$, and her belief could be based on that evidence as well as on E. In such a case, B might be doxastically justified, thanks to its dependence on the other basis. 
for a belief are called the subject's propositional justification for the belief, and I'll follow this usage here. ${ }^{20}$

Whereas the Doxastic Downgrade thesis is defined in terms of belief, the Propositional Downgrade thesis is not. If the amount of propositional justification provided by an experience $E$ is reduced below the baseline, then $E$ is epistemically downgraded in the sense tied to propositional justification. The corresponding downgrade thesis draws the link to checkered experiences like this:

\section{Propositional Downgrade Thesis}

If $E$ is a checkered experience with content $P$, then the propositional justification for $P$ provided by $\mathrm{E}$ falls below the baseline.

Arguably, the two downgrade theses are linked in the following way:

Linking thesis: If $B$ is based on a checkered experience with content $P$ and is thereby doxastically unjustified, then any propositional justification for $\mathrm{P}$ provided by that checkered experience would fall below the baseline.

Why believe the linking thesis? It is sometimes said that a subject's belief that $P$ is doxastically justified, just in case it is based on something that provides her with propositional justification for P. Jon Kvanvig explicitly defines doxastic justification in this way (and Feldman seems to concur):

Doxastic justification is what you get when you believe something for which you have propositional justification, and you base your belief on that which propositionally justifies it. $^{21}$

\footnotetext{
${ }^{20}$ For different usage, see Turri (2010), who argues that one has propositional justification for believing $p$ only if one has a way of forming a belief that $p$ well. In contrast, my definitions allow that an experience could provide propositional justification for believing $p$, but a belief formed on its basis could fail to be doxastically justified, due to its relationship to other mental states that the subject is in. I thank David Christensen for the following example. Suppose I base my mustard-belief on a mustard-experience, but I have a defeater (I learned yesterday that my houseguest has placed lots of fake food items in my fridge), and because of intense mustarddesire and wishful thinking, I completely ignore the defeater. So far, the belief is formed badly. But suppose I also have a defeater-defeater: what I know about the houseguest's religious convictions entails that he would never play tricks involving something yellow, and my knowledge of his religious views has nothing to do with why I ignored the defeater. My forming and maintaining my mustard-belief has a bad etiology, in that it isn't causally sensitive to my other beliefs in the right way. But arguably, because the defeater-defeater is in place, the mustard experience provides PJ for believing there's mustard.

${ }^{21}$ Kvanvig (2003). Feldman (2002) writes: S's belief that $p$ at time $t$ is justified (well-founded) iff (i) believing $p$ is justified for $\mathrm{S}$ at $t$; (ii) $\mathrm{S}$ believes $p$ on the basis of evidence that supports $p$.
} 
Suppose the subject who fearfully suspects that there's a gun in her fridge bases her gun-belief on her (checkered) gun-experience, and suppose, as per the Doxastic Downgrade thesis, that this belief is thereby doxastically unjustified. Can the checkered experience nonetheless provide propositional justification for the gun-belief? Not if Kvanvig and Feldman are right, since their theories of doxastic justification (DJ) predict that if the experience provided propositional justification (PJ) and the gun-belief is based on it, then the gun-belief would have to end up doxastically justified, at the level of the baseline.

The defense of the Linking thesis just sketched appeals to the relationship between DJ and $\mathrm{PJ}$ in general. A more restricted defense appeals the relationship between $\mathrm{DJ}$ and $\mathrm{PJ}$ in the special case of experience. According to the more restricted defense, if an experience provides PJ for believing a proposition $p$ (perhaps with the help of other factors), then a belief based on that experience will be doxastically justified. It relies on the assumption that forming a belief on the basis of a suitable experience can be a good way of forming beliefs. In cases of checkered experiences, the threat to the epistemic status of the belief is located upstream of experience, not in the use made by whatever evidence experience provides.

As they stand, however, neither of these proposals is adequate, because both ignore the holistic nature of doxastic justification. A belief could be based on a bit of propositional justification, but still be doxastically unjustified because it is insensitive to other beliefs the subject has. For instance, consider a model of defeat on which an experience retains some justificatory force even when defeated, and consider someone who has a defeater for their experience but bases a belief on it anyway. More complex examples involving defeated defeaters make the same point, without relying on that model of defeat. ${ }^{22}$

These complications, however, do not detract from the main idea behind both proposals about the relationship between propositional and doxastic justification. The main idea is that the contribution of PJ to DJ can be localized in such a way that if an experience provides PJ for believing a proposition $P$, then if a belief in $\mathrm{P}$ based on $\mathrm{E}$ isn't doxastically justified, that status (as not doxastically justified) will be due to some factor other than $\mathrm{E}^{23}$

${ }^{22}$ See the example two footnotes back, which illustrates how DJ can be holistic whereas PJ can be piecemeal.

${ }^{23}$ We can also consider how the linking thesis fares, if $\mathrm{PJ}$ is defined in terms of $\mathrm{DJ}$, as John Turri proposes in a recent paper:

Necessarily, for all $S, p$, and $t$, if $p$ is propositionally justified for $S$ at $t$, then $p$ is propositionally justified for $S$ at $t$ because $S$ currently possesses at least one means of coming to believe $p$ such that, were $S$ to believe $p$ in one of those ways, $S$ 's belief would thereby be doxastically justified. (p. X)

Even with the definitional priority going in this direction, checkered experiences that lead to doxastically unjustified beliefs don't have justificatory force. Turri is mainly concerned to identify conditions under which a subject (at a time) has any propositional justification for $p$ at all, rather than with the conditions under which a particular reason or type of mental state, such as experience, counts as providing propositional justification. Even if we suppose that the subjects in the pliers-gun example plausible does always "currently possess at least one means" 
If the linking thesis is true, then the weight of the DP rests on the Doxastic Downgrade thesis. And even if the only true Downgrade Principle is the doxastic one, this thesis has all the upshots described in section 1 remain. And besides, it is hard to see what is left of the notion of $\mathrm{PJ}$ provided by experience, if it allows that some experiences provide $\mathrm{PJ}$ for believing $\mathrm{P}$, yet are systematically prevented from generating doxastically justified beliefs that $P$. By that point, the idea that the experience is providing justification is watered down to an extreme.

\section{The Doxastic Downgrade thesis}

Clearly experiences can belong to causal chains linking their checkered past to perceptual belief. What's less obvious is whether checkered experiences are a conduit by which beliefs based on them become epistemically badly formed, due to the indirect influence of the checkering. The Doxastic Downgrade Thesis in effect says that checkered experiences are just such conduits. Are they?

Perhaps they would be, if beliefs based on checkered experiences also had to be based on the checkering process (or the psychological elements within it). But this claim about basing seems false, given the psychological assumption that adjusting the basis of a belief will dispose the subject to adjust the belief. This assumption is tied closely to the idea that the basis of a belief is the reason for which the subject has the belief, an idea that informs influential attempts to pin down the elusive basing relation. ${ }^{24}$ When we turn to checkered experiences, it is easy to imagine cases in which adjusting the checkering elements - e.g., losing the fear of a gun in the fridge that led to a gun-experience, or giving up on (or backing off from) preformationism - will not lead the subject to adjust the belief she already formed on the basis of the checkered experience. If you believed that there was a gun in your fridge on the basis of your fearful-suspicion-checkered experience, and were unaware that your gun-fear had checkered your experience, but then lost the fear, it wouldn't be psychologically abnormal for you to maintain your belief. As you'd put things from your point of view, you just 'saw' a gun in the fridge. ${ }^{25}$

of forming the gun-belief, it seems clear that none of these means will include the checkered experience, given that by hypothesis, basing the gun-belief on the checkered experience made it doxastically unjustified.

Turri wants to emphasize the importance of using your evidence well in belief-formation (and adjustment), not just in possessing it. His moral is that it isn't enough to have good reasons or evidence; you have to utilize them properly in reaching your belief. This move does not vindicate the idea that even after an experience becomes checkered, it can still be utilized properly.

${ }^{24}$ See for instance the causal and counterfactual theories of basing described in Korcz (1997) and (2010).

${ }^{25}$ Like all glosses on the basing relation, problems arise with this one if adjustability is made into a sufficient condition for basing (if adjusting $X$ makes you adjust $B$, then $X$ is a basis for $B$ ). For instance, getting new higher-order evidence about one's belief or its basis (such as evidence that experts disagree, or that you reasoned to $B$ improperly) might make it rational for you to 
Fortunately, we can assess the Doxastic Downgrade Thesis without settling whether a belief that is based on checkered experiences is thereby based on the checkering states. When we ask whether checkered experiences are doxastically downgraded by virtue of being checkered, what we're asking is whether experiences can serve as a carrier for forms of influence on belief (by fear, desire, suspicions, mood or other psychological factors) that are obviously epistemically bad. And we can approach this question by comparing checkered experiences with a kind of mental state that we know can generate irrational beliefs: doxastically unjustified beliefs. I'll sometimes call such beliefs "ill-founded". When ill-founded beliefs generate more ill-founded beliefs (for instance when you base belief B2 on ill-founded belief B1), do they do so by virtue of any features distinctive of beliefs, that experiences do not share? If so, that would undermine the idea that checkered experiences generate ill-founded beliefs, by virtue of their etiology. In contrast, if ill-founded beliefs generate other ill-founded beliefs exclusively by virtue of features that beliefs in general share with experiences, then that provides some reason to think that when experiences have etiologies that mirror those of illfounded beliefs, those etiologies of experience can make beliefs formed on the basis of the experience ill-founded.

We can thus use the following strategy to assess the Doxastic Downgrade Thesis: consider the features of beliefs that are not shared with experiences, and see whether those features play any role in making ill-founded beliefs transmit their ill-foundedness to subsequent beliefs formed on their basis. I argue that when we examine these distinctive features of beliefs, we find little reason to think that these features play any role in making it the case that ill-founded beliefs generate other ill-founded beliefs. That gives us reason to think that the features of beliefs by virtue of which they generate ill-founded beliefs are shared with experiences. And if those features are shared with experiences, then that's a reason to think that if ill-founded beliefs can generate other ill-founded beliefs, by virtue of their etiology, experiences can generate ill-founded beliefs, by virtue of having a checkered past.

How do beliefs differ from experiences? A major difference is that beliefs can be irrational, whereas experiences cannot be. Does the fact that ill-founded beliefs are irrational play any role in making it the case that such beliefs generate other ill-founded beliefs? We can sharpen this question. When a belief B1 generates an ill-founded belief B2, and B1 does so by virtue of its etiology, is that only ever because B1 itself is irrational?

No. To see why, let's look more closely at the ways in which beliefs can make other beliefs become ill-founded. Sometimes, when B1 is ill-founded and B2 is based on B1, B2 is thereby ill-founded as well. ${ }^{26}$ When this happens, B1 transmits its ill-foundedness to B2. This

adjust B, yet intuitively shouldn't be counted as part of B's basis. Thanks for Jim Pryor for discussion.

${ }^{26}$ This claim allows that an ill-founded belief might fail to transmit its ill-foundedness, when surrounding beliefs make it justified. (For discussion, see Feldman and Conee (2001). For instance, suppose an inattentive classmate tells you that that Plymouth is the state capitol of Massachusetts, but you forget that that's how you came to that belief. Meanwhile you have a false but justified higher-order belief that you learned the state capitols from proper schooling. According to Feldman and Conee, the Plymouth-belief is justified, even though ill-founded. But 
kind of transmission is analogous to contagion. First Jill has a cold, then she gives it to Jack, and now Jack has a cold too. First B1 is irrational, then B2 is formed on the basis of B1, and now B2 is irrational too.

But some beliefs transmit irrationality, without themselves being irrational. Often beliefs are based on clusters of other beliefs, rather than on single beliefs, and not every belief in the basing cluster need be irrational, in order for the subsequent belief to end up that way. If I rationally believe that I'm going to New Jersey today and irrationally believe that in New Jersey it is raining locusts, I can end up with an irrational belief that l'Il likely see some locusts when I get there, thanks in part to my rational belief about where I'm going.

So a belief need not be irrational, in order for it to generate a subsequent ill-founded belief formed on its basis. Thus the fact that experiences are never irrational does not preclude them from doing the same. In fact, irrational mental states can be entirely absent from the etiology of ill-founded beliefs. If spiders make me feel frightened, then when I form the rational belief (upon seeing one) that There's a spider, my fear can serve as a conduit by which that belief becomes an indispensable part of the basis for my belief that it's endangering me. Likewise, if your dog Mack makes me feel lucky, then I might base the belief that today is my lucky day on the rational belief that There's Mack. I don't need to have an explicit irrational belief that the spider is likely to harm me, or that Mack brings me luck when he's nearby, in order for my fear or my superstition (about Mack) to generate irrational beliefs that are partly based on perfectly rational beliefs about the presence of spiders or Mack. In these examples, my irrational beliefs about seeing locusts or being lucky or endangered depend on the rational beliefs, and they depend on them in ways that are hallmarks of the basing relation.

So far, I've focused on a major difference between beliefs and experiences: the former can be rational or irrational, whereas experiences cannot be. I've argued that beliefs need not be irrational, in order to make other beliefs formed on their basis ill-founded, and more generally, that beliefs can ill-founded, without having any irrational mental state in their etiology. But perhaps when beliefs make other beliefs ill-founded, they do so by virtue of other features that experiences lack. How else do beliefs differ from experiences?

A second difference is that beliefs but not experiences can be formed through explicit reasoning. But the fact that we can explicitly reason our way to beliefs does not seem relevant to whether the epistemic status of the belief is impacted by its etiology. Usually we don't explicitly reason our way to beliefs, yet the way in which the belief is formed can still impact its rational status. Many beliefs are formed by processes that unfold in the mental basement, putting them on par with experiences, with respect to automaticity. Most perceptual beliefs are like this, as are many ways of coming to know what other people want or intend to do, given perceptual and testimonial information about them. The default is to believe our eyes, and only in exceptional cases do we explicitly reason our way to what the environment is like, given the way it looks. The fact that beliefs can be formed explicitly does not seem to be what makes beliefs the kind of state whose forward-looking epistemic status can be affected by its etiology.

A third difference is that beliefs should be adjusted in response to evidence, whereas experiences are not subject to the same norm. Here we can distinguish a normative and a

even they could agree that sometimes, ill-founding makes a belief doxastically unjustified, and that such beliefs formed on their basis will thereby be ill-founded as well. 
psychological dimension of the putative disanalogy between belief and experience. The normative dimension of the disanalogy is: being subject to the norm of adjusting beliefs in response to evidence. This norm seems to apply only to beliefs. The psychological dimension of the disanalogy is: being adjustable in response to evidence. It is controversial in what sense, if any, one can decide what to believe, but nonetheless it is often thought that we have some kind of control over beliefs that we do not have over experiences. ${ }^{27}$

Along the normative dimension, the disanalogy is faint. While some beliefs are the output of explicit reasoning, most beliefs are not. Although experiences are not subject to a norm whereby one should adjust them in response to evidence, we are subject to epistemic norms specifying circumstances on which we should not rely on our experiences. ${ }^{28}$ Part of adjusting a belief in response to evidence is adjusting which propositions we are going to rely on, in (non-suppositional) reasoning and action. And we can cease to rely on experiences in reasoning and action, just as we can we can cease to rely on propositions that we previously believed, before we adjusted the beliefs to take account of new evidence. ${ }^{29}$

The disanalogy in the vicinity is thus not found in the normative dimension, but rather in the psychological dimension of being adjustable in response to evidence, or formed as the result of explicit reasoning. Beliefs can be so adjusted or formed, experiences cannot. It is not immediately obvious how such adjustability would explain why ill-founded beliefs transmit their ill-foundedness. But the idea seems worth exploring, since adjustability in response to evidence is a major disanalogy between beliefs and experiences.

Although in principle, beliefs can be adjusted in response to evidence, psychological factors such as self-deception or inadequate capacities for reasoning may make them difficult to adjust. A subject is faced with evidence, but the evidence doesn't have the impact on belief that it should: even in response to blatant evidence $E$ (a child's muddy handprints are all over the wall, or there before you is a not-very-complicated mathematical proof), you do not draw the obvious conclusion, even after reflecting, and instead draw a different conclusion that is not well-supported by $\mathrm{E}$. In the muddy handprint example, the parent ignores evidence for their child's misbehavior, maintaining belief that the child is innocent; in the math case the subject forms a belief that is not adequately sensitive to the proof. In each of these cases, it is difficult for the subject adjust beliefs to fit the evidence that she has. A different sort of example of the

${ }^{27}$ Compare Sosa (2007), p. 46: "Experiences are able to provide justification that is foundational because they lie beyond justification and unjustification. Since they are passively received, they cannot manifest obedience to anything, including rational norms, whether epistemic or otherwise."

${ }^{28}$ Perhaps we are also subject to norms specifying when we should rely on our experiences, on pain of irrationality. For instance, if you have no reason to disbelieve or refrain from endorsing your experience, doing so anyway is arguably unreasonable. For discussion, see Jackson (forthcoming).

${ }^{29}$ In the case of belief, being prepared to rely on a proposition in non-suppositional reasoning and action may be partly constitutive of believing it, whereas the analogous constitutive claim about experiences is almost certainly false. But even if this difference is granted, it does not entail a difference in the norms governing which propositions and experiences we should rely on. 
same kind of difficulty comes from factors that lead subjects to systematically ignore perceptual experience. $^{30}$

In these cases of self-deception and perceptual bias, subjects as a matter of fact cannot adjust their beliefs in response to evidence or experience, and perhaps couldn't do so, without a good deal of psychological upheaval. But it would miss the point to conclude from such cases that these beliefs are unadjustable in response to evidence, and so they are analogous to experiences after all. These cognitive limitations do not indicate any principled or systematic unadjustability of beliefs. If the subject weren't self-deceived, or were better at mathematical reasoning, then they could adjust their beliefs in response to evidence. So even these beliefs are disanalogous to experiences.

Does this disanalogy lie behind the transmission of ill-founded from one belief to another? It seems not. Even beliefs that are hard to adjust can remain ill-founded. The fact that these beliefs are not easily adjustable does not prevent them from transmitting their illfoundedness. A subject's difficulty in adjusting beliefs in these situations seems to have little impact on whether ill-foundedness can be transmitted. This suggests that adjustability in response to evidence does not explain why ill-founded beliefs transmit their ill-foundedness to subsequent beliefs formed on their basis.

A last difference between experience and belief is that some beliefs are dispositional, whereas experiences do not seem to have a dispositional form. This feature, however, does not seem relevant to enabling beliefs to transmit ill-foundedness. Even occurrent judgments that are ill-founded transmit their ill-foundedness.

Our examination of the disanalogies between belief and experience suggests that when ill-founded beliefs transmit their ill-foundedness, they do by virtue of features shared with experiences, rather than by virtue of features distinctive to beliefs. This conclusion in turn suggests that checkered experiences lead to doxastically unjustified beliefs, as per the Doxastic Downgrade Thesis.

\section{What is a checkered experience?}

${ }^{30}$ A fanciful example is given by Plantinga (1993) who imagines a climber who gets doxastically frozen: while rock-climbing, his beliefs about where he is and what he is doing become frozen, so that he continues to believe that he is on a mountain hanging on to rocks with birds circling overhead, even though (in an effort to help him unfreeze) his friends have brought him to an opera. As Plantinga describes the case, the climber has a series of visual and auditory experiences of the sort people have when they go to the opera, but these experiences make no impact on what he beliefs (he does not even self-ascribe them), and he continues to believe that he is rock-climbing. Depending on one's theory of belief and experience one might question the coherence of this example. But at least on a smaller scale, it seems possible for subjects to ignore experiences in their formation of beliefs, just as they ignore other kinds of evidence. For instance, if there are completely inattentive experiences, and such experiences can rationally support their contents, then they provide a realistic example. For discussion, see Siegel and Silins (forthcoming-b). 
So far, I've relied on an informal characterization of checkered experiences. It is time to characterize this kind of experience more carefully.

First, just to fix on a way of speaking, let us stipulate that the etiology of a psychological states includes the state that is its output: in our cases, either experience or belief. So when we ask whether an etiology is a-rational or rationally assessable, we are asking about the epistemic status of the entire transition to the output state from its causal antecedents.

What could it be for an experience to have a rationally assessable etiology, as opposed to one that is a-rational? Let me say right off the bat that the distinction between rationally assessable and arational etiologies won't and probably can't be drawn sharply, and large grey areas will remain. ${ }^{31}$ But for our purposes we could rely on paradigms of rationally assessable and arational etiologies, if there are any. I'm going to argue that there are.

The kind of rationally assessable etiologies of interest are internal to the subject's cognitive system. A different kind of etiology might seem rationally assessable, while involving other entities, such as a god or demon, that regularly cause experiences on the occasion of the subject having certain mental states. For instance, on the occasion of racist fears or bouts of overconfidence, a demon might produce a gun-experiences or experiences of approving expressions on a sea of faces. Such etiologies will not be candidates for rationally assessable ones in the sense at issue here, because they are not internal to the subject's cognitive system.

My proposal for understanding the distinction between rationally assessable and arational etiologies goes in stages, first finding the distinction for the case of etiologies leading to belief, and then using the case of belief to define the distinction for etiologies of experience.

\section{Etiologies of belief}

It is natural to think of etiologies of belief as processes that lead a subject to acquire the belief in the first place. But we can also broaden this notion to include three other kinds of processes: processes by which subjects adjust the beliefs they already have by becoming more or less confident in them; processes by which subjects maintain their beliefs without explicitly considering them (this could include ignoring evidence that's relevant to the belief, or ignoring factors that are irrelevant to the belief), and processes by which subjects explicitly re-affirm their levels of confidence (e.g., uninformative double-checking: you're pretty sure that you have your keys, and patting your pocket to double-check leaves you exactly as confident as you were to begin with: the bump you feel isn't strange enough to make you any less sure that you have your keys, but also isn't the kind of bump that makes you more certain that you have them either). ${ }^{32}$

${ }^{31}$ Part of what complicates the issue is the live option that some transitions between propositionally structured states are arguably a-rational (think of the schizophrenics conclusion that the end of the world is coming from their beliefs that the chess board is arranged thusand-so), and some associations between non-propositionally structured elements may be rationally assessable (associating danger with mice may be irrational, rather than a-rational). The structural difference between the elements in the transition may not settle which status the transition has.

32 This expanded notion of an etiology of beliefs suggests that it would be useful to expand the notion of doxastic justification as well, to preserve the idea that all beliefs have some epistemic 
In the case of belief, the distinction between rationally assessable and a-rational etiologies relies on two intuitive assumptions.

The first assumption is that even when beliefs are formed beneath the first-person radar, for instance when they arise from subpersonally employed heuristics, biases, or other inference-like processes, the fact that these processes occur down in the basement of the mind does not prevent us from assessing them as rational or irrational ways of forming beliefs. Inductions can be done well or badly, using appropriate or inappropriate samples as bases for projection. In principle, heuristics and biases may be more or less reasonable ones to use. Given a psychological hypothesis about the myriad processes by which our beliefs get formed, we are not prevented from asking whether these processes are rational, just by virtue of the fact that they are not cases of explicit deliberation of the sort that people undertake when they serve on juries, or plan a vacation, or produce philosophy.

In many cases, the psychological facts about which etiologies our beliefs have isn't known, and often it is controversial what sort of rational status they have. ${ }^{33} \mathrm{~A}$ standard example is the case made known by Tversky and Kahneman in which people make quite simple mistakes in probabilistic reasoning, even when the general principle of probability is wellknown to them. They judge that Linda, whom they were just told was a politically active philosophy major in college, is more likely to be a feminist bank teller than a bank teller. It is controversial which process people use to arrive at this judgment. But the status of the process as a heuristic does not rule out that it's the result of reasoning from some general principle across a wide range of cases (such as the assumption that information provided in a conversation immediately leading up to a question is relevant to the question) rather than an arational route to belief on par with being zapped by God.

The second assumption is that in some cases of forming (or adjusting or maintaining) beliefs, we would not regard either ourselves or any of our subpersonal systems as convicted of any error if we ended up with those beliefs via that kind of process, nor would we regard the processes as making the belief rational. Suppose that having been raised without lemons or depictions of them, you come to believe (using your relatively impoverished lemon-concept) that some lemons ripen red. You come to believe this, not because of faulty induction, but because God, or having the flu, or suffering an imbalance of neurotransmitters somehow directly zapped that belief into you, without instigating any intervening cognitive processes - no induction, no reliance on heuristics of any sort, no hearing any divine voice, no computation

status. Some beliefs might not have been formed, and aren't or maybe even can't be adjusted at all, because they are part of a cognitive infrastructure. Such beliefs might include the firstperson belief that you exist, belief that the external world exists, beliefs in intuitive physics or other components of 'core cognition', or beliefs (in the form of knowledge) concerning what you're doing when you're doing it. Despite the special status these beliefs may have, they can still have an etiology in the expanded sense. And if doxastic justification is having epistemically good etiology, then even these beliefs could in principle count as being doxastically justified. (On core cognition and its status as part of cognitive infrastructure, see Carey (2009). On knowing what you're doing, see Setiya 2008).

${ }^{33}$ For discussion, see Gigerenzer (2001). 
from any other states or properties. ${ }^{34}$ We would not regard you or your cognitive system as having made any error in arriving at that belief. Such zaps would be brute incursions from the divine or from the merely physiological domain.

In calling this second assumption intuitive, I'm laying it down as an intuition that there are etiologies leading to beliefs that cannot be rationally assessed, even if the beliefs they result in can be. Even if no beliefs are off the grid of epistemic norms, some processes leading to beliefs are. The idea that a process leading to belief could be a-rational is an intuition rooted in cases involving causation of beliefs by God or lightning bolts. This idea is meant to be primitive, in the sense that it is not analyzable in terms of the rational status of the output belief, or anything else. For instance, it's not true by definition that irrational beliefs have rationally assessable etiologies. Beliefs never fall off the grid of rational norms (there is no such thing as an a-rational belief), yet we can distinguish between a-rational and rationally assessable routes to belief.

For us what matters is the conceptual distinction between a-rational and rationally assessable etiologies leading to belief, and for the purpose of defending the coherence of this distinction, extreme and fictional cases are all that's needed. But are there any actual cases of a-rational etiologies leading to beliefs? It is hard to say. ${ }^{35}$ Candidates may include brainwashing and hypnosis, though it depends how those processes work. Perhaps some delusions involved schizophrenia have this status, such as the prima-facie incoherent belief some patients seem to express that they are thinking thoughts that are not their own, but that someone else has projected into their mind like a picture flashed on a screen. Or consider the belief a schizophrenic patient once reported that there were lizards growing in his chest, causing the skin on his arm to become scaly. ${ }^{36}$ You might doubt that these delusional beliefs have a-rational

${ }^{34}$ A complication: if even after the zap, you believed you had no way of knowing what color lemons ripen to be, that belief would arguably be a defeater for the zapped belief. So if you persisted in believing that lemons ripen red, then the lemon-belief would be irrational, not because of it's a-rational etiology, but because you were ignoring a defeater. We can eliminate this confounding source of irrationality by adding to the thought-experiment that God's zap also makes you believe (de dicto) that you have some way of knowing what color lemons ripen to be.

35 Mandelbaum, "Thinking is Believing" (in preparation) argues that a wide range of beliefs are formed and maintained a-rationally, drawing on belief perseverance studies (Wegner et al. 1985) as well as the Anchoring heuristic discussed by Tversky and Kahneman. Subjects who are asked to give numerical estimates (about how old Gandhi was when he died, for example) incorporate numerical information that they know to be irrelevant (such as their social security number) when the irrelevant information is salient. Mandelbaum argues that these processes are a-rational on the grounds that it is difficult to find anything that remotely resembles any paradigm of reasoning - even bad reasoning - in reconstructing the process by which participants arrive at their answers.

${ }^{36}$ Browning and Jones (1988). On thought-insertion, see Frith and Frith (2003). The metaphor of projection on a screen comes from a patient quoted by Mellor (1970): I look out the window and I think that the garden looks nice and the grass looks cool, but the thoughts of Eamonn 
etiologies because they are (crazy) responses to experiences: visibly scaly skin, or (perhaps) weird phenomenology of thought. But in principle, the lizard-delusion could come first, and a confirmation bias leads subjects to elaborate them by taking scaly skin to be a sign of lizards within. The result could be a belief with an arational etiology.

\section{Etiologies of experience}

With the distinction in hand between a-rational and rationally assessable etiologies for belief, we can define an analogous distinction for experiences as follows:

An etiology $X$ of experience $E$ with content $C$ is rationally assessable iff etiology $X^{*}$ of belief $B$ with content $C$ is rationally assessable, where $X^{*}$ has similar psychological elements as $X$, except it leads to belief without intervening experience.

Consider the examples we started with. Just as fearing or suspecting that there's a gun in the fridge or that Jack is angry could morph into believing these things, so too could fears or suspicions (or both together) produce a gun-experience upon looking in the fridge, or an angerexperience upon seeing Jack. Just as wanting preformationism to be true could morph into a belief that it is true, so too could wanting it to be true produce an embryo-experience in someone who looks under the microscope. The psychological elements in these etiologies of these experience are similar enough to etiologies of ill-founded beliefs make them rationally assessable.

What about cases where the experience is checkered by a belief with the same content as the belief it gives rise to? For instance, Jill believes that Jack is angry, this belief checkers her anger-experience, then when she sees Jack she forms the belief that he is angry. We can think of the analogous case for belief as a case of belief perseverance. Jill has the belief at a later time because she had it earlier and kept it. Considered as an etiology of belief, the process of belief perseverance is rationally assessable: epistemic conservatives say it can make a belief wellfounded, whereas opponents say that it can't. The Doxastic Downgrade Thesis, combined with rejecting epistemic conservatism, predicts that Jill's experience in this case is downgraded.

Once we move away from fictional examples, one might object that an etiology of experience could never be very similar to an etiology of belief without intervening experience. You wouldn't expect a sausage machine to be able to make M\&M candy using the very same mechanism. If experiences and beliefs are as different as sausages and M\&M's, one might think, then they just couldn't have very similar etiologies.

In reply, there are both a priori and experimental grounds for thinking that cognitive penetration of experience actually occurs, and that it occurs via processes that are similar to those leading to beliefs - both paradigmatically well-founded beliefs and paradigmatically illfounded beliefs. I won't repeat a priori arguments given elsewhere for the conclusion that properties besides, shape, illumination, motion are represented in visual experience, but we can reason as follows: if properties or kinds such as tree or pine tree are represented in visual

Andrews come into my mind. There are no other thoughts there, only his. ... He treats my mind like a screen and flashes thoughts onto it like you flash a picture." 
experience, then they are likely to be represented as a result of learning to recognize these properties, and to that extent their etiology will be rationally assessable. ${ }^{37}$ For instance, if you formed a belief that $X$ is a pine tree from being told that $X$ has certain kinds of leaves and structure, together with your knowledge of what features pine trees have, this way of forming the belief would be rationally assessable. It would also have the same structure as rationally assessable cognitive penetration, in which a perceptual input combines with prior knowledge of what pine trees look like to produce a pine-tree experience. These etiologies of pine-tree belief on the one hand and pine-tree experience on the other would be similarly structured, and would have similar psychological elements.

Besides a priori arguments about recognitional dispositions, some experiments suggest that prior expectations, knowledge, or stereotypes to influence the contents of perception, just as they can affect beliefs without intervening experience. A variety of other experimental results suggest that the etiology of experiences are structured by subpersonal states that operate like predictions about what the subject will experience given how the current preexperiential perceptual input fits into a pattern of past inputs. On some theories, sceneperception precedes object-perception, enabling subpersonal scene-based predictions (such as that bathrooms contain sinks, streets contain trees, kitchens contain fridges) to play a major role in the transition from low-level, pre-conscious states of visual processing, to categorization of objects. ${ }^{38}$ In color perception, knowledge that bananas are yellow (or perhaps, more weakly, things that greatly resemble bananas in their form) affects what color you see achromatic bananas (or achromatic banana-ish things) to be, suggesting that visual experience of a banana can be influenced by the prediction that it is going to be yellow. ${ }^{39}$ In lightness perception, racially ambiguous faces look lighter or darker depending on how they are racially classified. ${ }^{40}$

By themselves, these experiments do not tell us what mechanisms underlie these effects on experience, but they provide some evidence that there are such mechanisms. With good reason to think such mechanisms are in place, we can reasonably ask whether the processes leading to experience and ultimately also to belief are themselves the kind that lead to well-founded beliefs, as in the case of memory color, or to ill-founded ones, as they are in the (hypothetical) anger case.

Someone might object to the idea that there could be rationally assessable experiences on the grounds that a process wouldn't count as perception at all, if it didn't involve some merely causal inputs. ${ }^{41}$ In early work, Fodor (1975) observed that "some mental states are the result of brute incursions from the physiological level," and went on to give as an example "the causal determination of sensation" - as opposed to perception, which he assumed resulted from subsequent computations on sensory material. Whether or not one accepts Fodor's later architectural proposal, with its distinct roles for sensory transducers, input analyzers, and

${ }^{37}$ Siegel 2006-a.

${ }^{38}$ Bar. M. (2004).

${ }^{39}$ Hansen et al 2006. A similar result is reported in Goldstone (1995). For discussion, see Macpherson (forthcoming) and Deroy (2012).

${ }^{40}$ Levin and Banaji 2006.

${ }^{41}$ This suggestion might develop the idea that perception is passive whereas belief is active. 
central processing, there is an indispensable place for sensory transducers on any model of perceptual processing. If perceptual experience were exhausted by the result of this merely causal relation, then its etiology won't be rationally assessable. But brute causal incursions in the form of sensory transducers don't come close to exhausting the contents of perceptual experience. For a start, they don't represent constancies of size, shape or color. Phenomenologically, it seems as if perceptual experience is a straightforward input from the environment. But the phenomenology of direct contact is not a guide to the etiology of experience.

We can now define checkered experiences more carefully.

Checkered Experiences: An experience $E$ with content $C$ and etiology $X$ has a checkered past (or equivalenty, is checkered) iff:

- $\mathrm{X}$ is rationally assessable, and

- a belief with content $C$ and etiology $X^{*}$ would be doxastically unjustified, where the output of $X^{*}$ is a belief with no intervening experience, and $X^{*}$ has sufficiently similar psychological elements as $\mathrm{X}$.

The examples of cognitive penetration we began with all have etiologies that are similar to those of ill-founded beliefs. The examples could be described further in ways that would make them dissimilar to ill-founded beliefs. For instance, suppose that over the years, Jill's fear that Jack will get angry has triggers a learning process by which she gets better at detecting anger from facial cues, without many false positives along the way. ${ }^{42}$ Here the influence on belief by fear is mediated an ability to recognize anger on the basis of sensory input. In an analogous process that didn't involve sensory input, Jill's fear that Jack will get angry improves her theory of mind (or her theory of Jack's mind), making her good at figuring out what will make him angry. Anger-beliefs that are influenced by fear in this way are not, intuitively, ill-founded.

It is no simple matter to characterize the kinds of cognitive penetration that produce checkered experiences. The kind that operates through perceptual learning is not automatically exempt from checkering. Suppose that on a specific occasion, Jill's fear that Jack is (at that moment) angry at her penetrates her experience when she sees him, and he looks angry to her. This paradigm case of checkering (exactly the one introduced at the start of the paper) is compatible with Jill's being equipped with a largely reliable perceptual sensitivity to Jack's anger that she acquired partly as a result of fearing Jack, in something like the way that physically abused children become perceptually more sensitive to anger. ${ }^{43}$ Her perceptual learning might make her sensitive sensory inputs that others couldn't notice, in just the way a mushroom expert can distinguish between species of mushrooms that look the same to novices, yet on a specific occasion it might be her occurrent fear, rather than the sensory cues,

\footnotetext{
42 There is some evidence that perceptual learning can be triggered by emotion responses like this. Pollock and Sinha (2002) found that physically abused children "accurately identified facial displays of anger on the basis of less sensory input than did controls", which suggests that as the result of their exposure to threats by adult caretakers, they get better at detecting anger. The study did not speak to whether the learning also led to false positives.

${ }^{43}$ Pollock and Sinha (2002), op cit.
} 
that are mainly responsible for her anger-experience when she sees Jack. Illusion and veridical hallucination are both compatible with perceptual learning.

On the face of it, any type of cognitive penetration that operates through attention might seem exempt from checkering. For instance, many types of perceptual learning operate through attention, where gaining perceptual expertise changes which low-level features become salient. ${ }^{44}$ And by themselves, these types of perceptual learning seem epistemically innocuous. More generally, when prior mental states influence what you look at or attend to, without influencing how things look to you when you see them, the result might seem to be a mere selection effect. If you want the Necker cube or the duck-rabbit to shift, you can make it shift by adjusting your focus to the relevant part of the figure, thereby affecting the contents of your experience.

But some selection effects do not seem epistemically innocuous. In the pliers case, the black prime may direct attention first to those parts of the pliers that are gun-like, resulting either in a gun-experience, or a gun-shape experience which in turn combines with a background belief (or recognitional ability). In a search task for angry faces, white subjects find the black angry faces more quickly than they find white angry faces. ${ }^{45}$ While these selections of stimuli involve no illusion or distortion of local stimuli, they can lead to experiences that misrepresent the entire scene as one in which the only angry faces are black or the only relevant features of the stimulus are the gun-like ones. These selection effects can turn perceptual experience into an instrument of confirmation bias. Since there is nothing intrinsically bad, epistemologically, about ignoring some stimuli while processing others, the epistemological challenge is to explain what makes some selections but not others epistemologically.

Since the hopes seem slim for defining checkered experiences in terms of a special kind of cognitive penetration, it may be more promising approach to rely on our sense of which processes lead to ill-founded beliefs, and of which etiologies of experiences are structurally similar to those. Of course it is often controversial exactly what makes a belief ill-founded. But there are paradigm cases of ill-founded beliefs, and on the approach to checkering offered here, these illustrate a schema for identifying checkered experiences. Once we have that, we can work backwards and distinguish epistemically innocuous cognitive penetration, from at least one variety of epistemically compromising cognitive penetration.

On the approach offered here, having an irrational belief in the etiology of an experience is neither necessary nor sufficient for checkering the experience. It is not necessary, because checkering can arise from conative states alone (as in wishful thinking), and because (as we saw in section 2). In addition, even when etiologies of ill-founded beliefs include other beliefs, they not include any irrational beliefs. Together with the definition of checkered experiences, this entails that checkered experiences need not have unjustified beliefs in their checkered past. To see that having an unjustified belief in the etiology of experience is not sufficient for checkering, suppose you belief without justification that you are a hawk, and believing this greatly improves your visual acuity. The process is clearly a-rational, and so the resulting experience is not checkered.

\footnotetext{
${ }^{44}$ Goldstone (forthcoming).

${ }^{45}$ Otten and Banaji (submitted).
} 


\section{Objections and Replies}

I now turn to two objections to my case for the Downgrade Principle. Both objections focus on the cases of cognitive penetration with which I began. The first objection challenges the status of these experiences as lacking in justification, and the second charges that cognitive penetration could lead to epistemic downgrade, only with the additional controversial assumption that the contents of experience include 'high-level' properties such as being an embryo, a gun, a jar of mustard, or being angry.

\section{Objection 1: Reduced justification, or mere obstacle to knowledge?}

Upon considering the gun-in-the-fridge, preformationism, Ouija board, pliers/gun and anger examples, it is easy to have the immediate reaction that these experiences are somehow epistemically worse than the original mustard-experience, when you simply look in the fridge and learn that there's mustard in it by seeing the mustard. I've portrayed this reaction as an intuition that any justification these experiences provide for believing their content is reduced below the baseline - they are epistemically downgraded.

An opponent might object that I am over-describing the reaction. The only intuition in the vicinity, they might say, is more general: something is epistemically amiss in these cases, but it need not be that there's an epistemic downgrade of experiences. It could be that checkered experiences defeat knowledge, but they don't downgrade justification. Compare a veridical hallucination, in which you have a plain old hallucination of mustard in the fridge, and there just happens to be a jar of mustard in the fridge exactly in the place where you hallucinate one to be. If you believed the contents of your hallucination, you would end up with a justified true belief, but arguably not with knowledge. According to the objector, whatever prevents such a veridical hallucination from counting as knowledge also operates in our cases of cognitive penetration, and constitutes their only epistemic shortcoming. Cognitive penetration of the sort illustrated earlier introduces too much luck into perceptual beliefs for those beliefs to count as knowledge, they might say, but they do this without any reduction in baseline justification.

In reply, suppose the epistemic compromise is strictly analogous with the compromise in veridical hallucination - it has the same basic structure of a Gettier case, in which the experience is not properly connected to the facts. Then it will only apply to veridical checkered experiences, or more generally, to cases in which, according to the opponent, the proposition that the checkered experience putatively justifies is true, and the experience is not properly connected to it. But the original intuition was not sensitive to whether Jack really is angry, or there really is a gun in the fridge. So this restriction cannot explain what the epistemic compromise is in cases where the relevant propositions are false.

If the kind of knowledge-defeat in question is somehow expanded to include these cases, then it cannot accommodate the comparative dimension to the original intuition. Intuitively, Jill's fear-penetrated anger-experience puts her in a worse epistemic position than she would be, if she had an uncheckered anger-experience, all other things being equal. But if Jack really isn't angry, then Jill can't know on the basis of her anger-experience that he is, whether her experience is checkered or not. In contrast, if the checkered experience introduces an epistemic downgrade, then there is a clear respect in which Jill's checkered experience puts 
her in a worse epistemic position, compared to a situation that is otherwise the same except that the experience is uncheckered: she has less justification from her experience when it is checkered, than she has from her experience when it isn't.

\section{Objection 2: High-level contents}

At the start of the paper, I gave six examples in which I suggested that cognitive penetration leads to epistemic downgrade. In all but one case, the cognitively penetrated experiences represented properties more complex than color, shape, motion, illumination, such as being an embryo, being a mustard jar, and being angry. Someone might doubt that experiences can represent such complex properties. If complex properties like these cannot be represented in experiences, then not only are the examples misdescribed, but the possibility remains open that the experiences themselves are not epistemically downgraded at all. For instance, in the preformationism case, if the experience represents only a configuration of variously illuminated lines and colors, then one might think it provides justification at the baseline for believing that there is something on the slide with those features.

In reply, suppose that complex properties such as being a gun cannot be represented in visual experience. There will still be configurations of less complex properties that normally trigger representations of guns, and normally lead to beliefs that a gun is present. Call these configurations of low-level properties gun-gestalts. Experiences representing gun-gestalts will provide justification for gun-beliefs with the help of standing background beliefs or dispositions linking those low-level properties to guns, perhaps with the additional support from a belief that the scene is likely to contain a gun. ${ }^{46}$

In a simple kind of cognitive penetration, the penetrating state and the experience end up with the same contents, and both involve complex properties (such as the content that Jack is angry). ${ }^{47}$ We can see that none of the examples I've been working with rely on the assumption that experiences can represent complex properties such as being a gun, however, if we distinguish this kind of cognitive penetration from another kind, where the contents of penetrating state differ from the contents of the experience, in that the penetrating state's contents involve complex properties, but the contents of the penetrating experience do not. For instance, fear that there's a gun in the fridge could penetrate your experience by generating gun-gestalt contents, whereas without the fear, in a hum-drum case of looking into the fridge, your experience would have different non-complex contents (mustard-jar-gestalt contents, for example). In principle, a subject's could have a justified background belief (or a recognitional

\footnotetext{
${ }^{46}$ In earlier terminology, the experience just described will not provide immediate justification for gun-beliefs since the justification for believing that a gun is present will depend on both the experience and the background belief linking the low-level contents of the experience to guns.

47 In the preformationism case, since the experience represents a specific embryo, whereas the penetrating belief is that spermcells in general contain embryos. In the mood case, it's questionable whether the mood has any contents at all (perhaps it is instead a disposition to respond to a range of situations with negative affect and beliefs associated with discouragement), but even if they do, those contents are presumably not contents ascribing colors to things.
} 
disposition) linking gun-gestalts to guns. Any epistemic shortcoming would be due to the experience, which triggered the gun-misrecognition by representing a gun-gestalt. The Downgrade Principle would predict downgrade here, just as much as it would predict downgrade in a case with the simpler form of cognitive penetration. A hope (or a fear) that there is a gun in the fridge that morphed into a gun-belief would be a case of wishful (or fearful) thinking, and resulting belief would clearly be ill-founded. The etiology of the gun-gestalt experience will be similar to the etiology of a doxastically unjustified gun-belief, with the difference that the transition from gun-gestalt to gun spans the divide between experience and belief.

\section{Conclusion}

In this paper l've argued that cognitively penetration of experiences, like other aspects of perceptual processes that unfold in the basement, have a place in assessing perceptual beliefs as doxastically justified or unjustified. Discussions of foundationalism in epistemology have encouraged the idea that all epistemic appraisals trace back no farther than experience. Any processes leading up to experience, it was thought, are mere rumblings in the basement of the mind, irrelevant to our epistemic standing. I've attempted to undermine those ideas, by focusing on etiologies of experience that deserve to be considered irrational, and arguing that this kind of etiology can lead to epistemic downgrade. Most of the work in defending this thesis takes the form of explaining how a process leading up to experience could be rationally assessable at all. Once it is granted that the various irrational processes that unfold in the basement of the mind include ones that culminate in experience, irrational processes of cognitive penetration seem to belong to the category of processes that can lead to doxastically unjustified beliefs - whether such processes generate experiences along the way, or not.

\section{References}

Bar. M. (2004). "Visual Objects in Context." Nature Reviews: Neuroscience, 5. 617-629.

Browning and Jones (1988), "Ichthyosis and delusions of lizard invasion". Acta Psychiatrica Scandanavica 78: 766-67.

Carey, S. (2009) The Origins of Concepts. New York: Oxford University Press.

Chalmers, D. (2004) "The Representational Character of Experience". Reprinted in The Components of Consciousness. New York: Oxford University Press, 2010.

Chalmers, D. (forthcoming) Constructing the World. Oxford: Oxford University Press.

Christensen, D. (1994) “Conservatism in Epistemology” Nous 28 (1): 68-89.

Deroy, O. (2012) "Object-Sensitivity without Cognitive Penetrability of Perception" in special issue of Philosophical Studies, Ed. Berit Brogaard. 
Feldman (2002) Epistemology. Upper Saddle River, NJ: Prentice Hall.

Feldman and Conee (2001) "Internalism Defended" American Philosophical Quarterly 38: 1-18.

Fodor, J. (1975) The Language of Thought. Cambridge: MIT Press.

Fodor, J. (1983) The Modularity of Mind. Cambridge: MIT Press.

Fodor, J. (1984) “Observation Reconsidered” Philosophy of Science 51:23-43.

Foley, R. (2008) Working Without a Net: Essays in Egocentric Epistemology. New York: Oxford University press.

Frith, C. and Frith, U. (2003) Schizophrenia: A Very Short Introduction. New York: Oxford University Press.

Gigerenzer, G. (2001). "The Adaptive Toolbox", in Bounded Rationality: The Adaptive Toolbox. Eds G. Gigerenzer and R. Selten. Cambridge: MIT Press. 2001.

Goldman, A. (1988) "Strong and Weak Justification" Philosophical Perspectives 2, 51-69.

Goldstone, R. (1995) Effects of categorization on color perception. Psychological Science 5, 298304.

Goldstone, R. (forthcoming). Perceptual Learning. In M. Matthen, ed. Oxford Handbook for Philosophy of Perception.

Hansen et al. (2006) "Memory Modulates Color Experience". Hansen et al, Nature Neuroscience, vol. 9, no. 11.

Hansen, Thorsten and Gegenfurtner, Karl. R. (2008) Color scaling of discs and natural objects at different luminance levels. Visual Neuroscience, 23, 603-610.

Jackson, A. (forthcoming) "Appearances, Reality and Justified Belief" Philosophy and Phenomenological Research.

Korcz (1997) "Recent Work on the Basing Relation" American Philosophical Quarterly 34.2: 17192.

Korcz, Keith Allen, "The Epistemic Basing Relation", The Stanford Encyclopedia of Philosophy (Spring 2010 Edition), Edward N. Zalta (ed.), URL = <http://plato.stanford.edu/archives/spr2010/entries/basingepistemic/>. 
Kriegel, U. (2009) Subjective Consciousness: A Self-Representational Theory. Oxford: Oxford University Press.

Kvanvig, Jonathan. (2003) "Propositionalism and the Perspectival Character of Justification." American Philosophical Quarterly 40.1, pp. 3-18.

Levin and Banaji (2006) "Distortions in the perceived lightness of faces: The role of race categories." Journal of Experimental Psychology: General, 135, 501-512.

Lycan, W. (1988) Judgment and Justification. Cambridge Studies in Philosophy.

Lyons, J. (forthcoming) "Circularity, Reliability, and Cognitive Penetrability of Perception." Philosophical Issues.

Macpherson, F. (forthcoming) "Cognitive Penetration of Color Experience", in Philosophy and Phenomenological Research.

Mandelbaum, E. (ms) "Thinking is Believing"

McDowell, J. (2008). "The Disjunctive Conception of Experience as Material for a Transcendental Argument. In F. Macpherson and A. Haddock (eds.), Disjunctivism: Perception, Action, Knowledge. Oxford University Press.

Mellor, C. S. (1970). First rank symptoms of schizophrenia. British Journal of Psychiatry. 117: 15-23.

Otten and Banaji (submitted), "Automatic Race Attitudes Guide Attention in Visual Search".

Payne, B. K. (2001) "Prejudice and Perception: The Role of Automatic and Controlled Processes in Misperceiving a Weapon" Journal of Personality and Social Psychology 81, No 2.

Payne, B. K. (unpublished) "The Experience of Misperceiving a Weapon) (ms).

Peacocke, C. (2004) The Realm of Reason. New York: Oxford University Press.

Pinto-Correira, C. (1997) The Ovary of Eve. Chicago: University of Chicago Press.

Plantinga, A. (1993) Warrant and Proper Function. New York: Oxford University Press.

Pylyshyn, Z. (1999) "Is Vision Continuous with Cognition? The Case for Cognitive Impenetrability of Visual Perception" Behavioral and Brain Sciences 22: 341-365.

Pollak and Sinha (2002) Developmental Psychology, Vol. 38, No. 5, pp 784-791. 
Searle, J. (1983) Intentionality. Cambridge University Press.

Setiya, K. "Practical Knowledge", in Ethics 118, April 2008, 388-409.

Siegel and Silins (forthcoming-a), "The Epistemology of Perception". To appear in Oxford Handbook of Philosophy of Perception, ed. Mohan Matthen. New York: Oxford University Press.

Siegel and Silins (forthcoming-b), "Attention and Perceptual Justification". To appear in Stoljar and Pautz, eds. Festschrift for Ned Block. Cambridge: MIT Press.

Siegel, S. (2006a) "Which Properties are Represented in Perception?" in Gendler and Hawthorne, eds. Perceptual Experience. New York: Oxford University Press.

Siegel, S. (2006b) "Subject and Object in the Contents of Visual Experience" Philosophical Review 115:3.

Siegel, S. (2010) The Contents of Visual Experience. New York: Oxford University Press.

Siewert, C. (1997) The Significance of Consciousness. Princeton: Princeton University Press.

Silins, N. (2011) "Seeing Through the Veil of Perception". Mind.

Sosa, E. (2007) Reflective Knowledge Oxford University Press.

Turri, J. (2010) "On the Relationship between Propositional and Doxastic Justification". Philosophy and Phenomenological Research 80.2, March 2010.

Wegner, D. G. Coulton, and R. Wenzloff. (1985) "The Transparency of Denial: Briefing in the Debriefing Paradigm." Journal of Personality and Social Psychology 49 (2): 338-46/ 